\title{
Relação entre o estudo formal e a média salarial do músico: um estudo com músicos brasileiros
}

\author{
Relations between formal study and the musician's average salary: \\ a study with Brazilian musicians
}

\author{
Kássio Alves Mendes ${ }^{1}$ \\ Lívia Maria Dutra ${ }^{2}$ \\ Denise Perdigão Pereira ${ }^{3}$ \\ ${ }^{1}$ Universidade do Estado de Minas Gerais, Belo Horizonte, Minas Gerais, Brasil. \\ kassiomusico@yahoo.com.br \\ ${ }^{2}$ Universidade Federal de Minas Gerais, Belo Horizonte, Minas Gerais, Brasil. \\ liviadutra@ufmg.br \\ ${ }^{3}$ Universidade do Estado de Minas Gerais, Belo Horizonte, Minas Gerais, Brasil. \\ perdigaodenise@yahoo.com.br
}

\section{Resumo:}

O artigo tem como objetivo avaliar o mercado de trabalho relativo à Música, através da observância de vetores tais como: idade de iniciação musical, média salarial e grau de instrução formal dos mesmos. Trata-se de uma pesquisa quantitativa usando-se a técnica de coleta de dados, os quais foram obtidos por meio de um questionário estruturado respondido por 291 músicos brasileiros. A análise dos aspectos aqui tratados pode contribuir para o estabelecimento de uma projeção custo-benefício baseada na maior ou menor formação acadêmica, e atuação efetiva na área da música.

Palavras-chave: Músicos Brasileiros e salários; Formação Musical; Média Salarial. 


\begin{abstract}
:
This article aims at making observations about the musician's job market by assessing specific vectors, such as: which age they started music studying, their average salary and their formal instruction or lack of it. This is a quantitative research accomplished by means of data taken from a questionnaire, which was completed by 291 Brazilian musicians. Those issues may contribute to establish a projection of the benefit-cost ratio related to instruction and work in the area of Music.
\end{abstract}

Keywords: Brazilian Musicians and salaries; Musical Training; Average Salary.

Data de recebimento: 18/01/2015

Data de aprovação final: 23/09/2015

\title{
1 - Introdução
}

A influência exercida pela educação sobre o desenvolvimento e mobilidade social, bem como sobre o aumento da renda própria, é notoriamente grande e, de consequência, tem sido tema de muitos estudos. FIGUEIREDO (2006), ao investigar a educação superior e a mobilidade social, constatou que os níveis e os indicadores de educação, desenvolvimento e renda, são elementos intimamente relacionados entre si. Voltando o olhar para o campo da música, PICHONERI (2006) salienta a família como uma instituição importante no momento inicial de aproximação e incentivo ao estudo desta arte. Em sentido oposto, alguns educadores musicais observam que muitos alunos são desencorajados a estudar música por seus próprios familiares. Tal fato desperta certa curiosidade científica sobre o motivo pelo qual isso acontece, tendo em vista o papel que a educação exerce sobre o aumento da qualidade de vida.

Levanta-se, pois, diante dessa problemática, a seguinte questão: será que, no caso específico do profissional da música, o estudo proporcionará, tal como nas outras áreas, elevação do padrão de vida ou, mais especificamente, aumento de renda? Procurando responder a esta questão, a atual pesquisa busca sistematizar dados acerca do custo-benefício do estudo 
formal da música, e da atuação do músico profissional no contexto brasileiro. Tem também por objetivo averiguar se, aquilo que se verifica a nível nacional, acerca da relação entre os vetores estudo e renda, é encontrado também no campo específico da música. Para tanto, a pesquisa investigou a existência de traços de regularidade com base em uma amostra feita com 291 músicos brasileiros.

\section{2 - Metodologia}

Esta é uma pesquisa descritiva que teve como técnica de coleta de dados um questionário, o qual foi aberto em 18 de março de 2011 e fechado em 15 de junho do mesmo ano, quando o salário mínimo era de $\mathrm{R} \$ 545,00$ obedecendo à lei $\mathrm{n}^{\circ} 12.382$, de fevereiro de 2011 . O material base foi construído através do site SurveyMonkey, que funciona como uma ferramenta online para elaboração de pesquisas. Ao circular pela internet através de um link, o questionário é de livre acesso e pode ser respondido por qualquer pessoa. Desse modo, não houve uma seleção prévia daquelas que vieram a participar da pesquisa. No entanto, a amostra escolhida para o estudo é constituída por 291 músicos brasileiros ${ }^{1}$. Vale ressaltar que não é interesse aqui, avaliar os músicos entrevistados de acordo com regiões do país, e sim obter o cenário nacional da profissão e profissional.

Com o intuito de possibilitar o fornecimento, por parte dos músicos, das informações que viabilizassem o alcance dos objetivos propostos pela pesquisa, o questionário foi composto por perguntas relacionadas ao nível de instrução musical formal, média salarial, área de atuação, idade de iniciação musical, quantidade de fontes de renda, e idade atual até o momento de encerramento da coleta de dados. Também foram incluídas questões relativas à formalidade ou informalidade do trabalho a que se dedicam, bem como a opinião dos músicos em relação ao papel que o mercado de trabalho, no qual estão inseridos, exerce sobre o incentivo a um estudo curricular. Todas as análises foram feitas com a utilização dos softwares: Microsoft Office Excel 2007, Minitab 15 e R 2.15.1. Para detalhes técnicos

\footnotetext{
1 As respostas obtidas com o questionário estão abrigadas no banco de dados da empresa SurveyMonkey, empresa responsável pela ferramenta de elaboração de pesquisas. Todos esses dados podem ser acessados mediante solicitação enviada para o autor.
} 
relacionados à metodologia apresentada a seguir, podem ser consultados: TRIOLA (2008), MAGALHÃES e LIMA (2002) e GIOLO (2010).

\section{1 - Estatística Descritiva}

Para a realização da interpretação inicial dos dados, foi utilizada a estatística descritiva. Esse método tem como objetivo resumir as características importantes de um conjunto de dados. Foram construídos gráficos e tabelas, além do cálculo de algumas medidas de centro, conforme serão conceituadas a seguir.

Foram adotados nessa pesquisa os conceitos estatísticos abordados em TRIOLA (2008). Desse modo, entende-se como média a medida de centro encontrada pela soma de todos os valores amostrais, dividida pelo número de valores amostrais observados. A mediana é considerada como um "valor do meio", onde 50\% dos valores no conjunto de dados estão abaixo da mediana e a outra metade acima dela. Neste contexto, entende-se moda como sendo o valor que ocorre mais frequentemente no conjunto de dados. Embora a moda não seja muito utilizada em dados numéricos, ela é a única que pode ser utilizada com dados nominais entre as duas medidas de centro supracitadas, sendo, por esse motivo, relevante para essa pesquisa.

Por sua vez, o desvio-padrão é entendido como uma medida da variação dos valores em torno da média. É uma espécie de desvio-médio dos valores em relação à média. Para análise foi usado o gráfico de Pareto. Trata-se de um gráfico de barras para dados qualitativos, com as barras dispostas em ordem de frequência. A barra mais alta fica à esquerda, e as barras menores se afastam para a direita. Uma vez que as barras são alocadas de acordo com a frequência, o gráfico chama a atenção para as categorias mais importantes.

\section{2 - Testes Estatísticos}

Para a realização do cruzamento dos dados, e verificação de relações entre as variáveis estudadas, foram realizados testes de hipóteses. Em estatística, uma hipótese é uma 
afirmativa sobre uma propriedade da população. Um teste de hipótese é um procedimento estatístico baseado na análise de uma amostra, que avalia as afirmações feitas na hipótese.

No presente trabalho foi preciso utilizar métodos conhecidos como não paramétricos. Estes não exigem que se tenha conhecimento sobre as propriedades populacionais das quais a amostra foi retirada. Foram realizados, também, testes de hipóteses que avaliam as médias. Tais testes identificam se as médias de diferentes grupos são estatisticamente iguais, ou não.

\subsection{1 - Componentes de um teste de hipótese}

O passo inicial para um teste de hipótese é saber identificar as hipóteses nula e alternativa. A hipótese nula, representada por $\mathrm{H}_{0}$, é a afirmativa de que o valor de um parâmetro populacional é igual a algum valor especificado. Testa-se a hipótese nula a partir da suposição de que ela é verdadeira. A hipótese alternativa, representada por $\mathrm{H}_{\mathrm{a}}$, é a afirmativa de que o parâmetro tem um valor que, de alguma forma, difere da hipótese nula.

A estatística de teste é um valor utilizado para se tomar uma decisão com base na hipótese nula. Ela é encontrada através da amostra e, por fórmulas matemáticas, convertida para um valor padronizado. O nível de significância, representado por $\alpha$, é a probabilidade de se cometer o erro de rejeitar a hipótese nula quando ela é verdadeira. Para essa pesquisa, todos os testes foram realizados com um nível de significância de 5\%, sendo essa escolha baseada na literatura, onde este valor é o mais utilizado, e permite boas inferências. O procedimento padrão, num teste de hipótese, requer que seja sempre testada a hipótese nula, de modo que a conclusão inicial será sempre de rejeitar a hipótese nula, ou deixar de rejeitar a hipótese nula.

\subsection{2 - Teste de Kruskal-Wallis}

O teste de Kruskal-Wallis é um teste não paramétrico para três ou mais populações independentes. É usado para testar a hipótese nula na qual as amostras independentes provêm de populações com a mesma média. A hipótese alternativa é a afirmativa de que as populações têm médias que não são todas iguais. Ou seja: 
$\mathrm{H}_{0}$ : Os grupos possuem médias iguais.

$\mathrm{H}_{\mathrm{a}}$ : Pelo menos um grupo difere na média.

\subsection{3 - Teste de comparação múltipla}

Após a realização do teste de Kruskal-Wallis será possível rejeitar ou não a hipótese de que todos os grupos possuem médias iguais. Apesar disso, não se pode concluir qual grupo específico possui média diferente dos demais. Para isto há vários procedimentos que podem ser usados para a identificação daqueles que possuem médias diferentes. Nesta pesquisa, será utilizado o teste disponível no pacote "pgirmess" do software R 2.15.1. Este teste determina qual grupo é diferente, em média, com comparações simultâneas em pares. Aqueles pares de grupos que possuem diferenças observadas maiores do que um valor crítico, valor padronizado, são considerados estatisticamente diferentes.

\subsection{4 - Teste de Wilcoxon}

O teste da soma de postos de Wilcoxon é um teste não paramétrico para duas amostras independentes, utilizado para testar a hipótese nula de que os grupos amostrais são provenientes de populações com médias iguais. Através da hipótese alternativa é possível testar, não somente se as duas populações têm médias diferentes, mas é possível identificar também se um grupo possui média maior ou menor que o outro.

\section{3 - Tabela de Contingência $2 \times 2$}

É muito frequente, em pesquisas que envolvem dados, depara-se com variáveis qualitativas de interesse que podem refletir em categorias de informação. Dados de estudos nos quais a variável resposta é categórica são usualmente dispostos nas tabelas de contingência, na qual as frequências correspondem a duas variáveis. Uma variável é usada para categorizar linhas, sendo a segunda variável usada para categorizar colunas. Nesta pesquisa, serão apresentadas tabelas de contingência $2 \times 2$ de dupla-entrada. O termo "dupla-entrada" se justifica porque a tabela apresenta uma classificação cruzada de duas variáveis. Já a dimensão $2 \times 2$ se deve ao 
fato de ambas as variáveis apresentarem respostas em duas categorias. Especificamente para esta pesquisa, as respostas serão sempre "sim", ou "não".

\begin{tabular}{cccc}
\hline Categorias da & \multicolumn{2}{c}{ Categorias da variável Y } & \\
\cline { 2 - 3 } variável $\mathrm{x}$ & $\mathrm{j}=1$ & $\mathrm{j}=2$ & Totais \\
\hline $\mathrm{i}=1$ & $\mathrm{n}_{11}$ & $\mathrm{n}_{12}$ & $\mathrm{n}_{1+}$ \\
$\mathrm{i}=2$ & $\mathrm{n}_{21}$ & $\mathrm{n}_{22}$ & $\mathrm{n}_{2+}$ \\
\hline Totais & $\mathrm{n}_{+1}$ & $\mathrm{n}_{+2}$ & $\mathrm{n}_{++}=\mathrm{n}$ \\
\hline
\end{tabular}

Figura 1: Apresentação de uma tabela de contingência 2x2 (GIOLO, 2010).

Vale ressaltar que as frequências denotadas na tabela da Figura 1 por $n_{i j}(i, j=1,2)$ correspondem aos totais de indivíduos observados simultaneamente na i-ésima categoria da variável X, e j-ésima categoria da variável Y. Os estudos cujos resultados são dispostos em tabelas de contingência possibilitam realizar testes de hipóteses que avaliam a independência das duas variáveis de interesse, onde:

$\mathrm{H}_{0}$ : as variáveis linha e coluna são independentes.

$\mathrm{H}_{\mathrm{a}}$ : as variáveis linha e coluna são dependentes.

Afirmar que variáveis são independentes leva ao entendimento de que não existe relação entre elas. Caso seja estabelecida a presença de associação em uma tabela de contingência $2 \times 2$, pode haver o interesse em descrever a intensidade desta associação. Para tal, serão calculadas as Razões de Chances. Esta é uma medida de associação entre as variáveis.

\section{3 - Análise exploratória dos dados}

Para melhor compreensão e visualização das respostas obtidas na pesquisa, esta seção será destinada à análise descritiva dos dados coletados.

\section{1 - Idade de iniciação musical}


De acordo com o questionário, as variáveis quantitativas da pesquisa estão relacionadas à idade de iniciação dos estudos musicais, idade atual do entrevistado, e sua renda mensal. Desta forma, é possível calcular algumas medidas de centro e variação, para que os dados possam ser interpretados. De acordo com a tabela da Figura 2, constata-se que a média de idade para a iniciação musical é de 13 anos, sendo a respectiva mediana de 14 anos. Dessa forma, como essas medidas são próximas, pode-se dizer que não houve muitas respostas discrepantes relativas à idade com que os entrevistados começaram o estudo de música. Esta conclusão pode ser confirmada pelo desvio-padrão pequeno, igual a 5,5, ou seja, as idades de iniciação musical de todos os entrevistados estão bem distribuídas em torno da média.

\begin{tabular}{ccccc}
\hline & Média & Mediana & Moda & Desvio-padrão \\
\hline $\begin{array}{c}\text { Idade de iniciação aos } \\
\text { estudos musicais (em anos) }\end{array}$ & 13 & 14 & 11 a 20 & 5,5 \\
Idade atual (em anos) & 25 & 23 & 21 a 25 & 8,8 \\
Salário (em R\$) & 1410,00 & 995,00 & 500 a 1000 & 1291,00 \\
\hline
\end{tabular}

Figura 2: Tabela das características gerais das variáveis quantitativas.

No gráfico da Figura 3, vê-se que pouco mais de $68 \%$ dos músicos entrevistados começaram os estudos musicais entre 11 e 20 anos. A porcentagem de músicos que começaram os estudos acima de 20 anos é baixa, menos que 5\%. Nenhum dos entrevistados declarou ter começado a estudar música com mais de 40 anos.

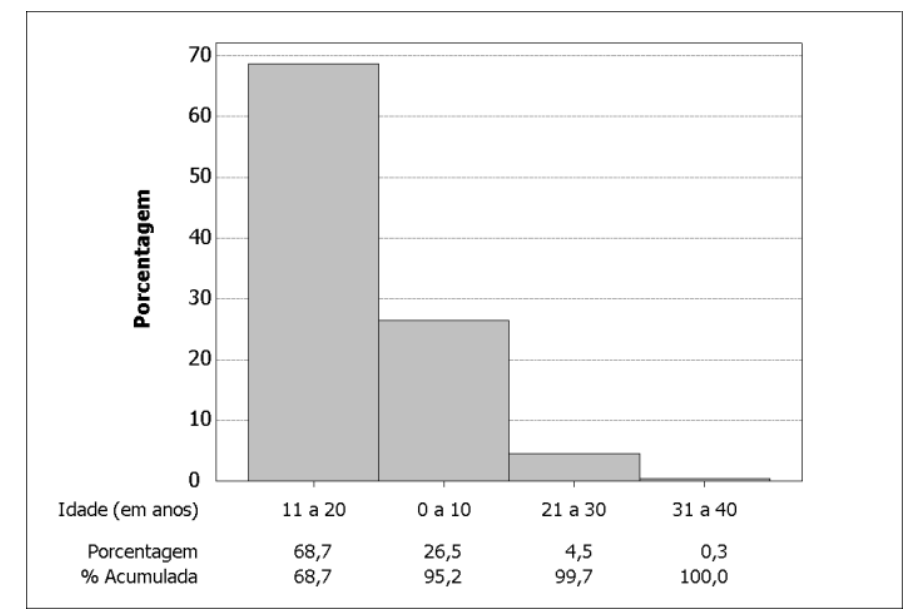

Figura 3: Gráfico de Pareto da idade de iniciação musical dos entrevistados. 


\section{2 - Idade dos entrevistados}

Analisando a variável idade atual, observa-se, de acordo com a tabela da Figura 2, que a idade média dos entrevistados, até o momento do fechamento do questionário, era de 25 anos, e a mediana, 23. Mesmo sendo valores próximos, há alguns entrevistados com idades mais elevadas que afetam o cálculo da média. Nesse caso, o desvio-padrão apresentou um valor igual a 8,8. Dentre as opções no questionário relativas à idade atual, a resposta mais obtida para esta variável foi de 21 a 25 anos.

O gráfico da Figura 4 indica que pouco mais de $65 \%$ dos entrevistados possuem idade entre 16 e 25 anos, e $30 \%$ deles estão com idade entre 16 a 20 anos. Estes não poderiam ter concluído ainda uma graduação, tendo em vista a idade mínima exigida para o ingresso em um curso superior no Brasil, e o tempo mínimo para conclusão do mesmo. Os músicos com mais de 41 anos representam menos de $4 \%$ dos entrevistados. A idade máxima é de 60 anos.

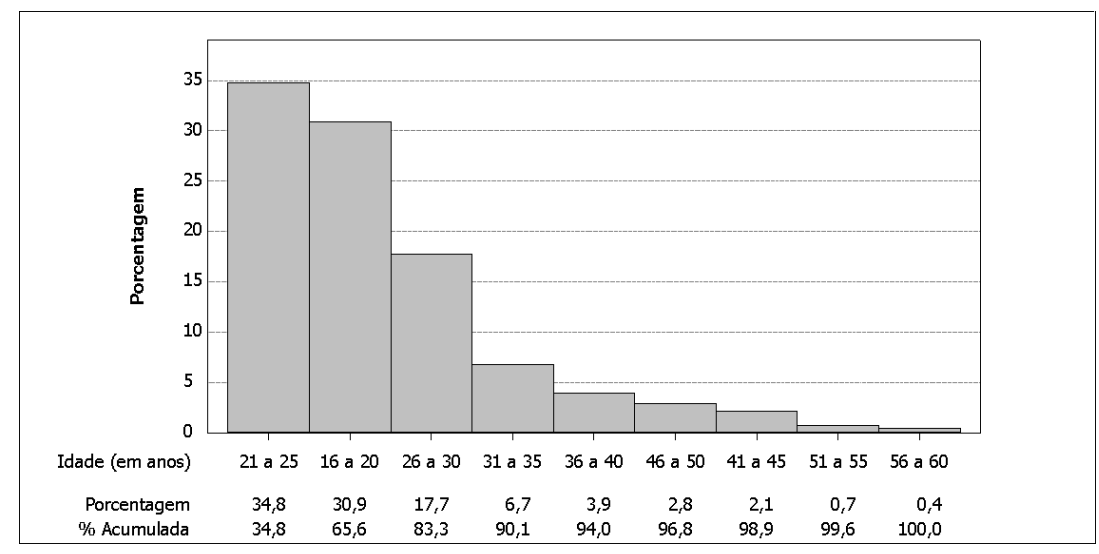

Figura 4: Gráfico de Pareto da idade atual dos entrevistados.

\section{3 - Nível de estudo formal}

O gráfico da Figura 5 apresenta a distribuição dos entrevistados em relação ao nível de estudo formal, em música. Vê-se que 21,3\% dos músicos entrevistados não possuem nenhum estudo formal. Os graduandos representam 25,1\%, divididos entre as modalidades bacharelado $(13,4 \%)$ e licenciatura $(11,7 \%)$. Músicos sem graduação, mas com algum tipo de estudo formal, representam $33,3 \%$. 
Há um total de 20,3\% de graduados. Desta forma, pode-se considerar que, para cada cinco músicos entrevistados, um é graduado. Neste último grupo também estão incluídos os músicos pós-graduados. Nenhum entrevistado possui doutorado completo como grau máximo.

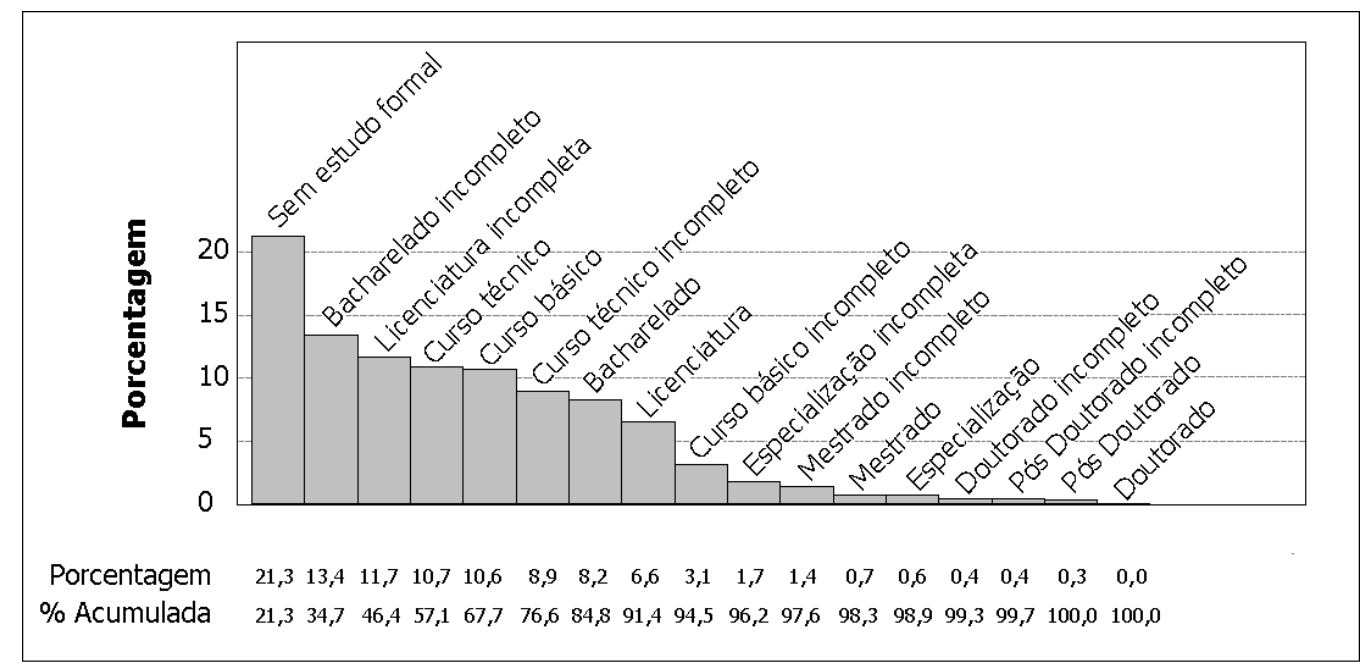

Figura 5: Gráfico de Pareto da formação musical dos entrevistados.

O gráfico da Figura 5 mostra que menos de 3\% dos músicos entrevistados chegaram à pósgraduação. Para que seja possível analisar o perfil dos músicos de acordo com o nível de estudo formal, é preciso reagrupar tais níveis, obtendo assim, tamanhos amostrais estatisticamente suficientes. Por esta razão ficaram em um mesmo grupo aqueles que possuem características semelhantes das variáveis em estudo. Após análise, optou-se por agrupar os músicos com especialização incompleta e completa num só conjunto, e, em outro conjunto, todos os músicos com mestrado completo, doutorado e pós-doutorado, sejam eles incompletos e completos.

\section{4 - Área de atuação}

Para análise da área de atuação, os músicos foram questionados em qual área mais se dedicam. O gráfico da Figura 6 mostra que pouco mais de $90 \%$ dos entrevistados atuam predominantemente como instrumentistas, professores ou cantores. Pode-se dizer que as duas principais áreas de atuação dos músicos entrevistados são de performers, totalizando 
$59,5 \%$, e professores, com $33,3 \%$. Os regentes representam apenas $2 \%$ do total. Outro dado importante é o fato de que $1,7 \%$ dos entrevistados declararam atuar como compositores, e 3,4\% atuarem em outras áreas da música.

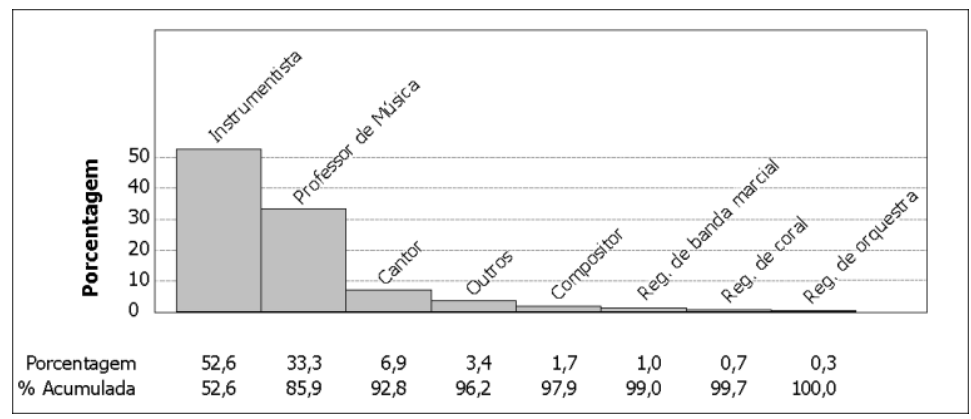

Figura 6: Gráfico da área de atuação dos entrevistados no mercado de trabalho.

\subsection{1 - Atuação e característica de formação}

No gráfico da Figura 7 é curioso notar que a maior porcentagem dos músicos que atuam como instrumentistas/cantores está no grupo dos entrevistados que declararam não ter concluído o nível básico do estudo formal, em música. É importante lembrar que a ordem na qual os cursos aparecem no gráfico da Figura 7 não representa, necessariamente, progressividade em relação ao estudo formal.

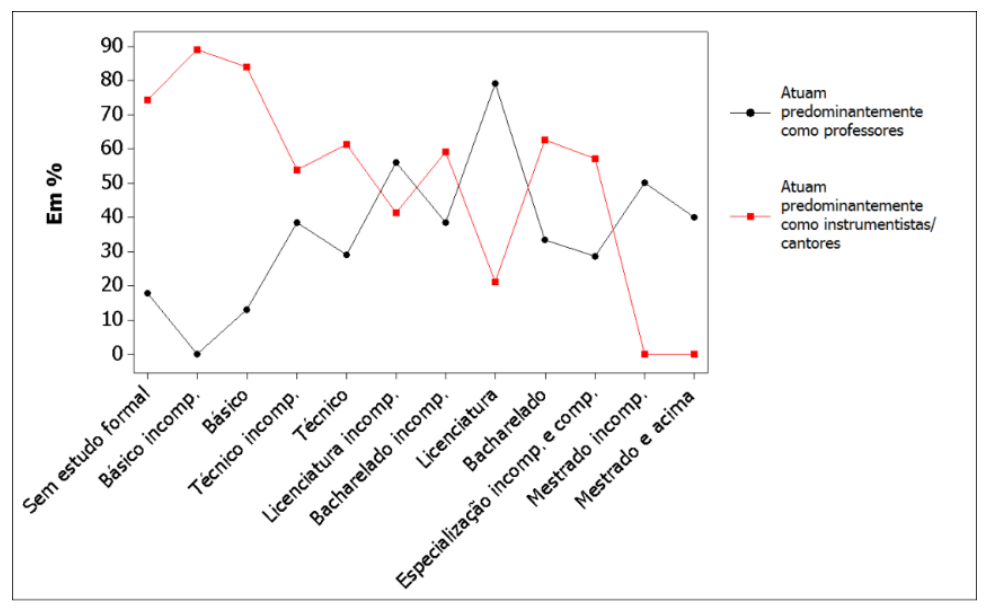

Figura 7: Gráfico da área de atuação de acordo com o nível acadêmico.

Percebe-se que as menores porcentagens de pessoas atuando como instrumentistas/cantores são encontradas nos cursos direcionados à pedagogia musical. Encontramos neste grupo, 
obviamente, a maior porcentagem de professores, o que é coerente em relação aos objetivos destes cursos. Atinente aos que fizeram pós-graduação, mestrado ou doutorado, nenhum entrevistado declarou atuar predominantemente como performer.

Percebe-se que a porcentagem de bacharéis que atuam como professores $(33,3 \%)$ é maior que a porcentagem de licenciados que declararam atuar no campo performático (21\%). Isso sugere que o bacharel, além de atuar como performer, faz concorrência ao licenciado, e que este, por sua vez, não tem conseguido contrapor-se a essa concorrência no campo da performance. Outro dado interessante revelado pelo gráfico da Figura 5 é o fato de que se verificou uma maior procura pelo curso de bacharelado do que licenciatura.

\section{Professores sem estudo formal}

Pouco mais de um quinto do total de entrevistados, $21,3 \%$, declarou não possuir nenhum estudo formal em música. Destes, 17,7\% declararam atuar predominantemente como professores. Eles representam 3,8\% do total de entrevistados.

A lei n 3.857 de 1960, que regulamenta a profissão de músico, estabelece como única condição para o exercício da profissão a aprovação em exame da Ordem dos Músicos do Brasil (OMB). A lei não indica nenhum pré-requisito para o candidato submeter a este teste. Neste ponto parece ser preciso sistematizar os conhecimentos acerca dos conteúdos e metodologias utilizadas na formação de professores, e de que forma inseri-los mais tarde no mercado de trabalho.

\section{A informalidade do estudo na performance}

Mesmo no grupo de entrevistados que não possuem nenhum estudo formal, a porcentagem de pessoas atuantes no campo da performance é maior, se comparado ao grupo dos bacharéis, ou seja, os profissionais que possuem formação específica para a atuação performática. Este grupo, por sua vez, tem uma porcentagem de pessoas atuantes como instrumentistas/cantores bem próxima daquela que aparece no grupo de pessoas com nível técnico. Assim sendo, posto que a porcentagem de performers num determinado grupo não varia em relação ao tipo de instrução, ou nível de estudo formal, não há indícios de que a atuação performática esteja diretamente relacionada a estes vetores. 


\title{
3.5 - Renda
}

Na Figura 8, vê-se que menos da metade dos músicos entrevistados $(42,4 \%)$ possui um trabalho formal. Apesar da baixa porcentagem, 80,3\% deles possuem renda mensal fixa. Neste caso é possível, desde logo, levantar a hipótese de que a formalidade, ou informalidade do trabalho, não está diretamente relacionada ao fato de se ter, ou não, renda fixa. As possibilidades que o músico tem de oferecer seus serviços de maneira informal torna possível que ele desfrute de uma renda mensal fixa, sem que seu trabalho seja formalizado.

Apenas $22,1 \%$ possuem uma única fonte de renda, e é alta a porcentagem de entrevistados que possui três ou mais fontes de renda $(44,8 \%)$. Este dado pode ser um reflexo da insegurança vivida pelo profissional da arte em função da instabilidade do mercado. Pode também ser um indício de que muitos destes músicos se encontram insatisfeitos com sua renda mensal e procuram, portanto, complementá-la com outras atividades. Outro indício dessa insegurança e descontentamento está no fato de $75 \%$ dos músicos entrevistados acharem o mercado de trabalho, no qual estão inseridos, desfavorável ao ensino de música.

A falta de uma situação social que favoreça e motive o estudo de música é abordada por ESTEVAM (2010):

\begin{abstract}
Além da unilateralidade em sua concepção e do uso frequente de estereótipos para formular modelos que explicam a desigualdade veiculada pela escola, o conceito de fracasso escolar apresenta-se interligado a outro aspecto importante a ser observado, como o não desenvolvimento de uma política voltada para a valorização do ensino de música (compatível com as novas demandas socioculturais dos alunos). O ensino de música ainda é visto, na maioria dos casos, como simples habilitação técnica, como "complemento" da educação, como forma de facilitar a aprendizagem de outras disciplinas, etc. ESTEVAM (2010, p.38)
\end{abstract}

PICHONERI (2011, p.164-166), em um estudo sobre os músicos da Orquestra Sinfônica do Teatro Municipal de São Paulo, discute aspectos importantes quanto à inserção dos mesmos no mercado de trabalho. De acordo com a autora, o universo pesquisado revela dois elementos que merecem especial atenção, a saber: o estado precário das relações de trabalho, e a insatisfação do músico com sua remuneração. A autora percebe que, como numa estratégia de sobrevivência, estes músicos se dedicam a outros tipos de trabalhos que não 
estão diretamente relacionados à sua formação (PICHONERI, 2006). A autora ainda constata que o trabalho alternativo encontrado pelos músicos da Orquestra do Teatro Municipal de São Paulo não pode ser considerado como artisticamente prestigioso, ou que ponha em evidência a virtuosidade do músico profissional.

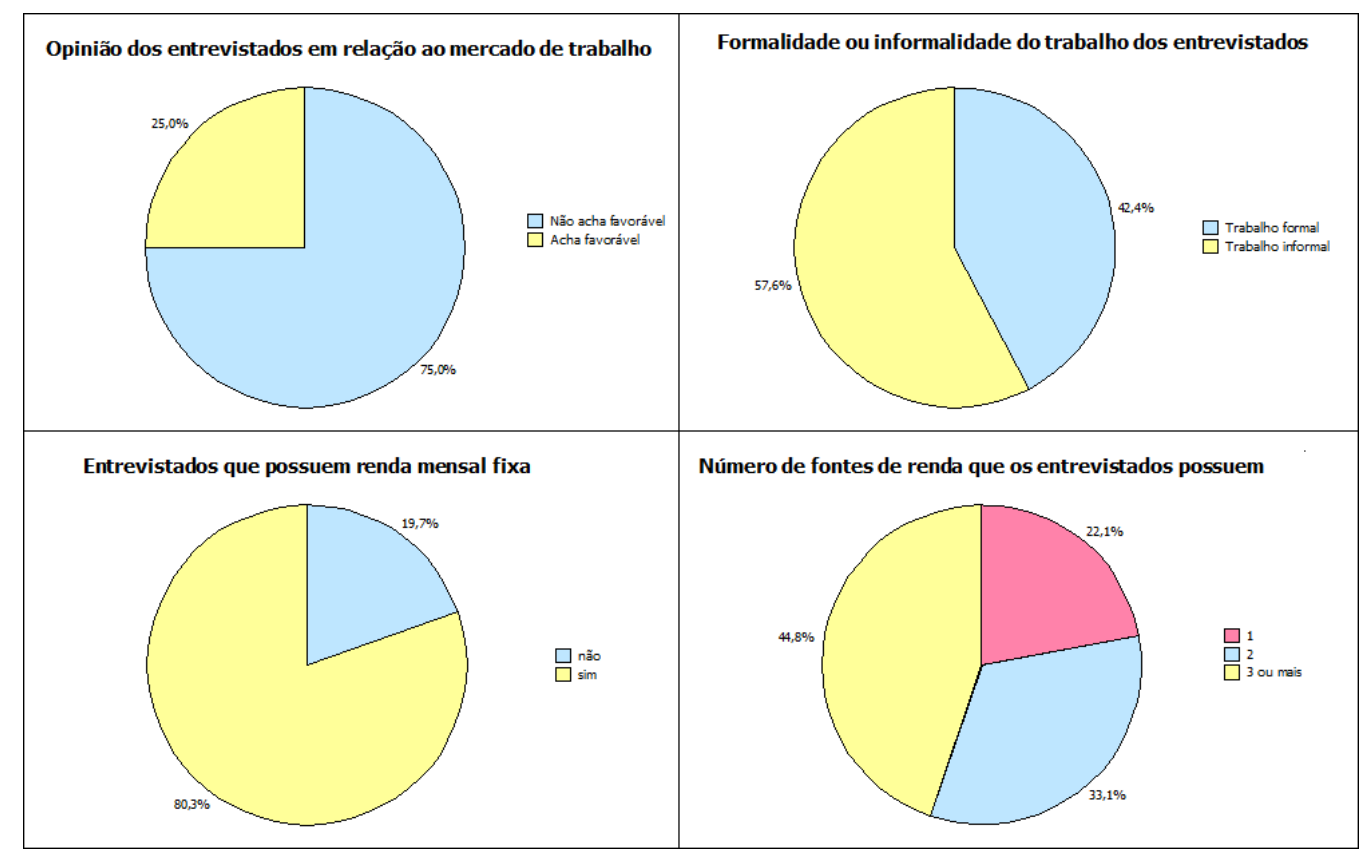

Figura 8: Gráficos de Setores de algumas variáveis da pesquisa.

A autora aponta ainda que a docência também faz parte do repertório de possibilidades às quais o músico performer lança mão, em busca de um aumento de renda. Isso ajuda a entender o caminho que tem levado tantos bacharéis, e demais performers rumo à sala de aula. As informações obtidas por PICHONERI (2006), embora coletadas num universo de pesquisa mais restrito, reforçam o argumento sobre a insatisfação e insegurança dos músicos, em relação ao mercado de trabalho.

\subsection{1 - Renda média e mediana}

O salário médio dos músicos entrevistados é de $\mathrm{R} \$ 1410,00$. No entanto, é preciso considerar que esse valor médio foi afetado por valores de salários muito altos em relação à maioria dos demais entrevistados. Como consequência há uma elevação do desvio-padrão que explica essa diferença. Assim, o cálculo da média salarial, neste caso, não diz muito da realidade da 
remuneração dos músicos, já que, a maior parte dos entrevistados declarou possuir uma renda mensal fixa entre $\mathrm{R} \$ 500,00$ e $\mathrm{R} \$ 1000,00$. Percebe-se, também, que o valor dessa média salarial é bem diferente do valor de sua mediana, ou seja, $50 \%$ dos entrevistados ganham até $\mathrm{R} \$ 995,00$.

Uma questão importante a ser mencionada é a seguinte: aos músicos participantes dessa pesquisa não lhes foi posta nenhuma questão sobre a jornada média de trabalho diário. Isto torna impossível mensurar, apenas com estes dados, o peso do salário.

\subsection{2 - A concentração e a não uniformidade da renda}

Conforme apresentado na Figura 8, 80,3\% dos entrevistados declararam possuir renda fixa, e o gráfico da Figura 9 foi construído com base nesta parcela dos músicos. Nele se verifica que pouco mais da metade declarou ter renda mensal de zero a 1000 reais, e que $9,1 \%$ dos músicos desta pesquisa possuem salário superior a 3000 reais. Daí se conclui que as rendas mensais estão mais concentradas nos valores mais baixos. No entanto há músicos que declararam possuir renda mensal superior a 6000 reais. Estes somam 2,2\% do total de entrevistados.

O gráfico da Figura 9 explica, portanto, visualmente, o que foi apresentado na tabela da Figura 2: há uma grande variabilidade no tocante ao valor da renda dos músicos, sendo que a média difere bastante da mediana. Portanto, utilizar apenas a média salarial encontrada para inferir sobre a realidade da renda mensal dos músicos não seria satisfatório. Vale ressaltar que este gráfico não é disposto em ordem sequencial de renda, mas sim por grupos que deram maior número de respostas.

Uma vez que há uma grande variação entre os salários, levanta-se a hipótese de que hajam grupos distintos, os quais podem explicar tal comportamento. Para discutir esse aspecto com mais precisão, os entrevistados foram, em seguida, agrupados de acordo com o nível de formação acadêmica. Esta separação, a princípio, é hipotética, apesar de ser este o elemento que, de fato, permite verificar se existe relação entre a média salarial e o nível de instrução formal em música: o que é o objetivo central da presente pesquisa. 


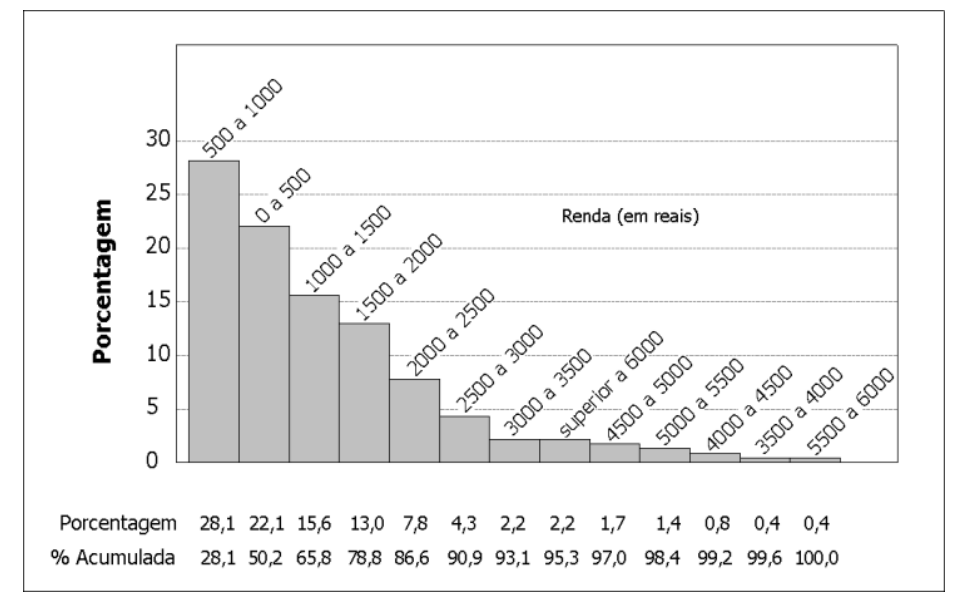

Figura 9: Gráfico de Pareto da renda mensal fixa dos músicos entrevistados.

Pela tabela da Figura 10, os grupos de músicos sem graduação, com exceção daqueles que possuem curso básico incompleto, a mediana da renda mensal é muito diferente da média, o que significa que existem valores muito discrepantes entre os salários. Da mesma forma observa-se que, na maioria dos grupos, a média salarial encontrada está fora dos valores de remuneração mais declarados. Um exemplo disso está no grupo de entrevistados com especialização. Neste caso a resposta mais frequente quanto à renda mensal foi entre $1000 \mathrm{e}$ 1500 reais. Considerando-se que a média salarial encontrada foi de 2370 reais, assim, o desvio encontrado nesse grupo é alto. Vale lembrar que quanto maior o valor do desviopadrão, mais os valores diferem da média.

\subsection{3 - Faixas de remuneração}

Se considerarmos os grupos de entrevistados que não possuem graduação, não há crescimento salarial aparente, se comparados aos que têm estudo formal, e a renda média oscila de forma aleatória. Já nos grupos de músicos com graduação - licenciatura e bacharelado - há uma aparente diferença da média salarial em relação aos não graduados. $\mathrm{O}$ mesmo se verifica nos grupos de pós-graduados em relação aos graduados. Dessa forma se podem observar três faixas de remuneração relacionadas a três grandes grupos, relativos ao grau de estudo formal: não graduados, graduados e pós-graduados. 
Ainda com relação a tabela da Figura 10, os grupos de entrevistados que apresentam maior uniformidade de renda são os que possuem curso básico incompleto, mestrado incompleto e mestrado a pós-doutorado. Observa-se também que, em todos os grupos, a porcentagem de músicos com renda fixa é superior a $65 \%$, sendo que, nos grupos de mestrado incompleto a pós-doutorado, $100 \%$ possuem renda fixa. Desta forma é possível afirmar que a carreira de música proporciona, sim, renda fixa, e que um músico que buscar uma pós-graduação stricto sensu terá grandes chances de adquirir estabilidade financeira.

\begin{tabular}{|c|c|c|c|c|c|}
\hline & $\begin{array}{c}\text { Entrevistados } \\
\text { que possuem } \\
\text { renda fixa (\%) }\end{array}$ & Média & Mediana & Moda & Desvio-padrão \\
\hline Sem estudo formal & 72,6 & 1100,00 & 800,00 & 500,00 a 1000,00 & 1136,00 \\
\hline Básico incompleto & 66,7 & 660,00 & 670,00 & 500,00 a 1000,00 & 376,00 \\
\hline Curso básico & 67,8 & 1330,00 & 800,00 & 500,00 a 1000,00 & 1630,00 \\
\hline Técnico incompleto & 73,1 & 1170,00 & 910,00 & 500,00 a 1000,00 & 750,00 \\
\hline Curso técnico & 84,0 & 1400,00 & 1290,00 & 1000,00 a 1500,00 & 1037,00 \\
\hline $\begin{array}{l}\text { Licenciatura } \\
\text { incompleta }\end{array}$ & 91,2 & 1120,00 & 880,00 & 500,00 a 1000,00 & 983,00 \\
\hline $\begin{array}{l}\text { Bacharelado } \\
\text { incompleto }\end{array}$ & 74,4 & 970,00 & 780,00 & 0,00 a 500,00 & 763,00 \\
\hline Licenciatura & 89,5 & 1720,00 & 1630,00 & $\begin{array}{l}500,00 \text { a } 1000,00 \mathrm{e} \\
1000,00 \text { a } 1500,00\end{array}$ & 1082,00 \\
\hline Bacharelado & 91,7 & 2060,00 & 1830,00 & 500,00 a 1000,00 & 1496,00 \\
\hline $\begin{array}{l}\text { Especialização } \\
\text { (incompleta e } \\
\text { completa) }\end{array}$ & 85,7 & 2370,00 & 1500,00 & 1000,00 a 1500,00 & 2131,00 \\
\hline Mestrado incompleto & 100,0 & 2120,00 & 2000,00 & 1500,00 a 2000,00 & 479,00 \\
\hline $\begin{array}{l}\text { Pós-graduação de } \\
\text { nivel mestrado a pós- } \\
\text { doutorado }\end{array}$ & 100,0 & 5400,00 & 5370,00 & 5000,00 a 5500,00 & 487,00 \\
\hline
\end{tabular}

Figura 10: Tabela das estatísticas descritivas da renda mensal de acordo com o nível de estudo formal.

\section{6 - Estudo e renda}

No gráfico da Figura 11 é possível constatar que a média salarial dos grupos dos músicos que não possuem graduação está abaixo da média salarial geral. Verifica-se, também, que todos os grupos dos graduados estão acima dessa média geral, e que a média mais alta é relativa ao grupo de pós-graduação nível mestrado ao pós-doutorado. Se considerar apenas as médias salariais descritas no gráfico abaixo, pode-se levantar a hipótese de que há uma 
diferença de renda de acordo com o nível de estudo formal do músico, por grupos maiores: não graduados, graduados e pós-graduados stricto sensu.

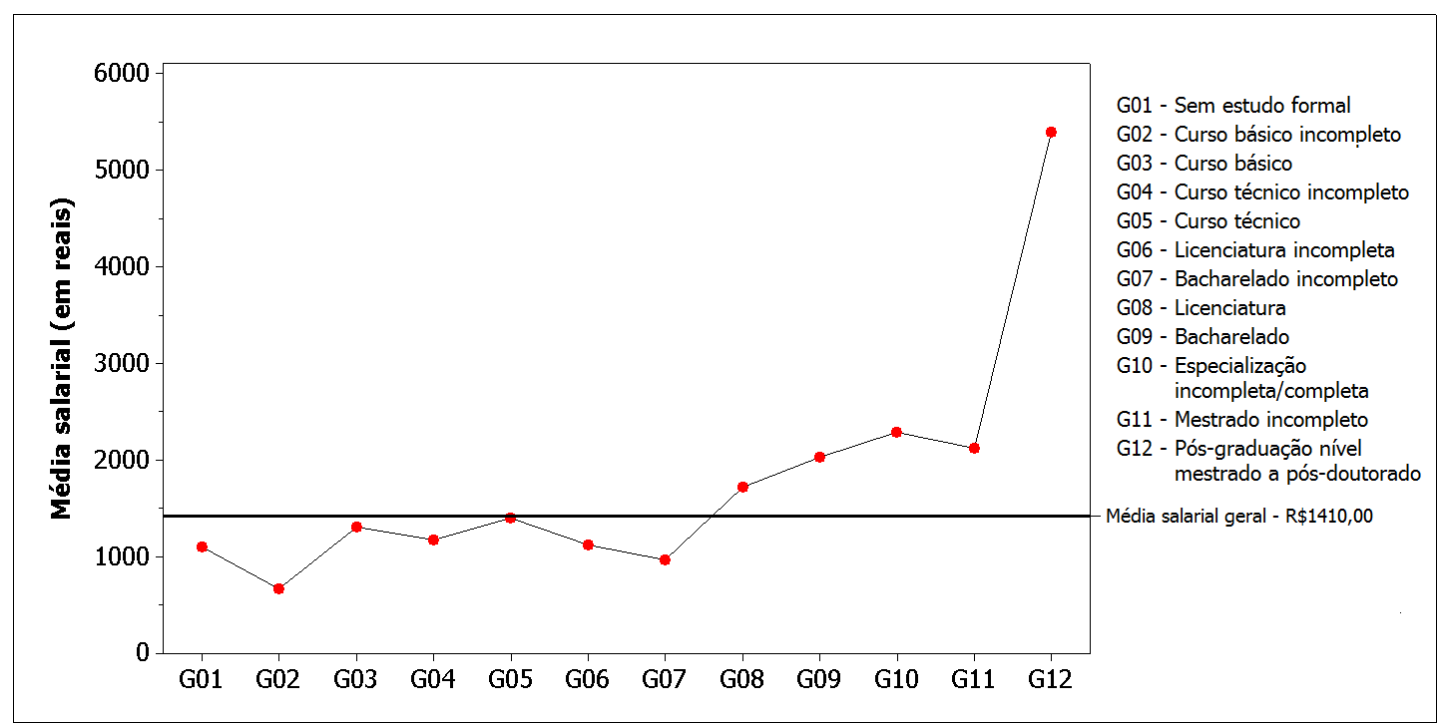

Figura 11: Gráfico da média salarial por nível acadêmico em música.

A partir da análise exploratória dos dados, constatou-se que, apesar de haver uma média salarial entre os músicos entrevistados, esta média foi afetada por valores, na maioria, muito discrepantes. Os dados acerca da realidade da renda desses profissionais são, à priori, inconclusivos. Entretanto é possível dizer que, entre os músicos entrevistados, a concentração de renda está entre os valores mais baixos.

Os dados fornecidos pela pesquisa permitiram a construção de uma série de hipóteses acerca da atuação de um grupo de músicos brasileiros no mercado de trabalho. Para que se saiba se essas hipóteses, e as possíveis relações encontradas nesta seção, são verdadeiras, a seção seguinte será destinada à utilização de técnicas que permitirão afirmar se estas relações são estatisticamente significantes, e se as hipóteses são verdadeiras.

\section{4 - Cruzamento de dados}


Esta seção visa cruzar os dados da pesquisa, e realizar testes estatísticos para verificar a viabilidade das hipóteses levantadas com a análise exploratória dos dados. Essas hipóteses são: 1) Com base nos dados relativos à renda mensal fixa, e a formalidade do trabalho, levantou-se a hipótese de que esses dois vetores não estão relacionados; 2) Com base nos dados relativos ao valor da renda fixa, a opinião dos entrevistados sobre quanto o mercado de trabalhado favorece o estudo desta arte, e também nos apontamentos feitos por PICHONERI (2006), levantou-se a hipótese de que este tipo de profissional sente-se inseguro com o mercado de trabalho, e que esta insegurança provém da instabilidade do mesmo mercado; 3) Ao verificar a existência de uma grande variedade relativa ao valor da renda dos entrevistados, surgiu a necessidade de, como procedimento de análise de dados, selecionar grupos distintos que expliquem este comportamento, bem como a causa das variações; 4) Constatando a existência de um eventual crescimento da renda do músico, numa relação direta com estudos formais, pode-se levantar a hipótese de que esses dois vetores - renda e estudo formal - estão relacionadas.

\section{1 - Relações entre renda e estudo}

Uma primeira análise foi realizada dividindo os entrevistados em doze grupos distintos, de acordo com o nível acadêmico. Os grupos foram separados conforme está indicado na tabela da Figura 10. Utilizando o teste de Kruskal-Wallis com 5\% de significância, rejeita-se a hipótese de que todos os grupos possuem médias iguais. Verifica-se, assim, que realmente há pelo menos um grupo cuja renda mensal difere estatisticamente da média.

Como há pelo menos um grupo diferente em média, foi preciso realizar um teste de comparação múltipla, com o objetivo de confirmar o resultado obtido pelo teste de KruskalWallis. Como resultado da análise em pares, foram encontradas evidências estatísticas de que o grupo dos entrevistados que possuem pós-graduação stricto sensu difere dos grupos sem estudo formal, curso básico incompleto, curso básico completo, licenciatura incompleta e bacharelado incompleto.

Torna-se assim, evidente, a progressão salarial relacionada ao grau de estudo formal, mas ela se encontra apenas no grupo de entrevistados que possui pós-graduação stricto sensu. No 
entanto, todos os outros pares de grupos que foram comparados, com um nível de $5 \%$ de significância, não rejeitam a hipótese de igualdade. É, portanto, possível afirmar que todos os outros grupos possuem médias salariais estatisticamente iguais.

De acordo com o teste realizado anteriormente, percebe-se que não há diferenças salariais significativas entre os diferentes graus de estudo formais. Por esse motivo foram construídos novos grupos para testar, uma segunda vez, se há diferenças salariais. Como foi dito anteriormente, os entrevistados foram divididos em quatro novos grupos. O primeiro deles constituído pelos entrevistados que declararam não possuir nenhum tipo de estudo formal. Os outros três foram divididos em: 1) não graduados; 2) graduados; 3) pós-graduados stricto sensu.

Para melhor compreensão, o grupo classificado como não graduados foi composto pelos entrevistados com curso básico completo ou incompleto, curso técnico completo ou incompleto, licenciatura e bacharelado incompletos. O grupo dos graduados foi constituído com os entrevistados que declararam possuir licenciatura, bacharelado, especialização completa ou incompleta e mestrado incompleto. E os pós-graduados stricto sensu são todos aqueles que possuem mestrado, doutorado completo ou incompleto e pós-doutorado completo ou incompleto.

Após esta última divisão, o teste Kruskal-Wallis foi novamente realizado. Com 5\% de significância, surgiram evidências de haver pelo menos um grupo cuja renda mensal é diferente, em média. De acordo com o teste de comparação múltipla, o grupo sem estudo formal não difere do grupo dos não graduados, mas ambos possuem média salarial diferente dos graduados e pós-graduados. E a renda mensal média dos entrevistados graduados e pósgraduados é estatisticamente igual.

Diante disso, pode-se concluir que existem dois grandes grupos que determinam médias salariais diferentes. São eles: 1) os músicos não graduados - aqui estão inclusos também aqueles sem estudo formal - e; 2) os músicos graduados. Como já foi dito anteriormente, no gráfico da Figura 11, todos os subgrupos que pertencem ao grupo dos músicos não graduados possuem média salarial abaixo da média geral. Analogamente, todos os subgrupos dos 
músicos graduados possuem média salarial superior a média geral. Os testes estatísticos provaram a suposição feita visualmente.

Dessa forma os resultados confirmaram, na área da música, os apontamentos feitos por FIGUEIREDO (2006) e PERES (2010) no âmbito geral brasileiro, quando estes relacionam o estudo formal à mobilidade social e o crescimento de renda. Conclui-se, pois, que o músico não graduado terá grandes chances de aumentar a sua renda mensal se investir na própria graduação.

\section{2 - A insegurança do músico em relação ao mercado}

Ao avaliar a independência das três variáveis presentes no quadro da Figura 12, segundo teste de hipótese, verificou-se que a variável trabalho formal está relacionada à variável renda fixa, bem como com a opinião do músico quanto ao mercado de trabalho como motivador de estudo. Com relação às variáveis que apresentaram dependência é possível medir a sua relação com o cálculo da Razão de Chances.

\begin{tabular}{|c|c|c|c|c|c|}
\hline & \multicolumn{2}{|c|}{ Renda fixa } & \multicolumn{2}{|c|}{$\begin{array}{l}\text { Acha o mercado } \\
\text { favorável ao } \\
\text { estudo }\end{array}$} \\
\hline & & $\mathrm{Sim}$ & Não & Sim & Não \\
\hline \multirow{2}{*}{ Trabalho formal } & $\operatorname{Sim}$ & 40,9 & 5,1 & 14,4 & 31,6 \\
\hline & Não & 38,5 & 15,5 & 8,6 & 45,4 \\
\hline \multirow{2}{*}{ Renda fixa } & Sim & ----- & - ---- & 19,6 & 59,8 \\
\hline & Não & ----- & ------ & 3,4 & 17,2 \\
\hline
\end{tabular}

Figura 12: Quadro de tabelas de contingência 2x2 sumarizadas, valores em \%.

Os dados desta pesquisa apontam que a chance de uma pessoa que está inserida num trabalho formal, achar o mercado favorável ao estudo de música, é 2,41 vezes maior em relação àquela que não tem trabalho formal. Isso pode indicar que o músico da área informal - que são a maioria, representando $57,6 \%$ do total de entrevistados - não se sente seguro e satisfeito com o mercado informal. PICHONERI (2011, p.103-105) afirma que o aumento e a diversificação das atividades dos músicos são motivados pela busca por estabilidade e aumento de renda. Daí pode-se concluir que esse comportamento tem sua origem na luta da classe para alcançar segurança. 
Conforme exposto no quadro da Figura 12, a chance de um músico possuir renda fixa com trabalho formal é 3,18 vezes maior do que se ele não o tiver. Isto contradiz a hipótese levantada na seção anterior, segundo a qual o trabalho formal não está relacionado com a renda fixa. Isso é aparentemente óbvio, mas a visão da realidade mostra que existem traços de regularidade com o mercado, dentro de uma concepção geral. Apesar de haver algumas diferenças, o mercado da música obedece à lógica geral do mercado. Não é um fato isolado, mas se integra, como todos os demais setores, num contexto social. Esta última observação não faz senão reforçar o laço que há entre os resultados aqui encontrados, e as constatações feitas por PICHONERI (2006 e 2011).

\section{3 - Relações entre renda e a quantidade de fontes de renda}

Em virtude dos indícios de descontentamento do músico em relação ao mercado de trabalho, evidenciado pela análise dos dados e estratégias utilizadas por estes profissionais para aumentarem a própria renda em busca de melhor estabilidade financeira, fatores apontados por PICHONERI (2006), é fácil notar a importância da seguinte avaliação: saber se a média salarial está ou não relacionada com o número de fontes de renda que o músico possui. Só assim pode-se verificar se as estratégias adotadas por este profissional são assertivas.

Com este intuito foi realizado um teste de hipótese de Kruskal-Wallis para três grupos distintos: 1) músicos com uma fonte de renda; 2) com duas fontes de renda, e; 3) três ou mais fontes de renda. Com 5\% de significância, a hipótese de igualdade foi rejeitada. Assim, há evidências de que, pelo menos, um dos grupos possui média salarial diferente dos outros. Pelo teste de comparação múltipla observou-se que não há diferença entre os grupos 1 e 2 . Ambos, porém, diferem da renda mensal dos músicos que possuem três ou mais fontes. Para poder avaliar se esta diferença significativa resulta em salários maiores ou menores, foi preciso realizar um novo teste de hipótese. Foram formados dois novos grupos, assim divididos: 1) músicos com uma ou duas fontes de renda, e; 2) músicos com três ou mais fontes de renda. 
O teste realizado foi o de Wilcoxon, no qual $\mathrm{H}_{0}$ é a hipótese de igualdade entre as médias, e $\mathrm{H}_{\mathrm{a}}$ a hipótese de que a média do grupo 1 é menor que do grupo 2 . Com $5 \%$ de significância, tem-se que os músicos com três ou mais fontes de renda têm uma média salarial maior do que aqueles que possuem uma ou duas fontes apenas. É, pois, assertiva a estratégia de variar as fontes de renda com o propósito de aumentar o bem-estar. Não é possível, porém, tirar conclusões sobre a estabilidade gerada em função disso.

\section{4 - Relações entre a renda e formalidade do trabalho}

Como os músicos entrevistados, e que declararam possuir renda fixa, estão divididos em duas classes - os que possuem trabalho formal e os que não o tem - foi importante avaliar a situação deles no mercado de trabalho. O intuito é descobrir se existe ou não uma diferença salarial entre os dois grupos e, caso esta diferença exista, qual deles possui melhor renda. Para tanto, o teste de Wilcoxon, para médias, foi utilizado e, com 5\% de significância, rejeitou-se a hipótese nula de igualdade da média dos grupos. O teste levou à seguinte conclusão: os músicos que possuem um trabalho formal tem um salário estatisticamente maior do que aqueles com trabalhos apenas informais. Com base nas constatações feitas por ESTEVAM (2010, p.38) pode-se afirmar que uma política pública que busque atender ao aumento da demanda escolar no que se refere ao estudo de música, seria assertiva, desde que estipulasse o acesso do músico ao trabalho formal como um de seus pilares.

A maior remuneração oferecida pelo trabalho formal também põe em evidência, sob esse prisma, uma participação do estudo formal no crescimento da renda, uma vez que os editais e processos seletivos tendem a ser mais exigentes quanto aos pré-requisitos da titulação, e da escolaridade destes profissionais.

\section{5 - O salário dos performers versus o salário dos professores}

Como mostra a Figura 8, 77,9\% dos músicos entrevistados possuem mais de uma fonte de renda. PICHONERI (2006) verificou que muitos músicos performers, em seu universo de pesquisa, têm recorrido à sala de aula para aumentar a própria renda. É importante, pois, verificar se esta estratégia é assertiva. 
Por ter sido levantada a hipótese de que o bacharel concorre com o licenciado na procura pela sala de aula, e que este último não tem conseguido responder à altura com a concorrência no âmbito performático, é importante fazer uma comparação salarial entre eles, no universo desta pesquisa. Para compreender se, no intuito de aumentar a renda, dispondo de mais de uma fonte, existe assertividade para o músico bacharel expandir sua área e atuar como professor e, em contrapartida, um músico licenciado passar a atuar também na área performática, nesta seção será feito um teste de hipótese para a média salarial dessas duas grandes áreas de atuação.

A avaliação foi feita somente entre os músicos entrevistados que são bacharéis e licenciados, e que atuam, predominantemente, como professores ou performers, para saber se uma dessas categorias proporciona melhor salário em relação à concorrente. O teste de Wilcoxon foi utilizado mais uma vez e, com 5\% de significância, Ho não foi rejeitada. Ou seja, não há diferença estatisticamente significativa entre a renda mensal média de professores e performers. Portanto dizer que o fato de um músico performático procurar a sala de aula com o intuito de aumentar a sua renda não implicará em aumento efetivo desta. Ele apenas aumentará o número de suas fontes de renda. Da mesma forma, na hipótese de que o licenciado não esteja conseguindo responder à concorrência oferecida pelo bacharel, isto não significa, necessariamente, prejuízo em sua renda.

\section{5 - Conclusão}

Considerando os estudos de FIGUEIREDO (2006) e PERES (2010) que relacionam o estudo formal à mobilidade social e o crescimento de renda, no âmbito geral brasileiro, viu-se a necessidade de verificar se estes indicadores se aplicam também ao universo da música. Esta pesquisa teve como objetivo realizar apontamentos sobre o mercado de trabalho de música e contribuir para o estabelecimento de uma projeção custo-benefício baseada na maior ou menor formação acadêmica e atuação efetiva na área da música. 
A partir da análise dos dados conclui-se que os indicadores que relacionam o estudo formal ao crescimento de renda do brasileiro encontram correspondência no âmbito musical. Foi possível, nesta pesquisa, identificar faixas de remuneração que variam em decorrência dos graus de estudo, como exemplo, a diferença de renda entre os graduados, e não graduados. Da mesma forma, em análise por subgrupos, foi constatado que os grupos sem graduação têm média salarial inferior aos demais, e os grupos com graduação estão acima da média. Dessa forma, o vetor estudo formal desempenha um papel direto no aumento da renda do músico brasileiro.

PICHONERI (2006) constata que a construção da rede de contatos desempenha um papel relevante no desenvolvimento da carreira profissional, por propiciar maiores chances de atuação no mercado de trabalho, independentemente do âmbito onde ela seja construída, quer seja no âmbito formal, quer seja no informal, performático ou docente. Dentro dessa perspectiva, o músico possui melhores chances de aumentar a própria renda, e estabilidade, quando é maior a procura pelo seu trabalho, estando esta procura diretamente relacionada ao tamanho de sua rede de contatos. Esta constatação é evidenciada pela presença do fator quantidade de fontes de renda como um dos vetores que determinam o seu aumento.

Sendo o trabalho formal um dos indicadores que se relacionam com o aumento da renda do músico, intui-se aqui também o papel indireto do vetor estudo no desenvolvimento desse indicador. Uma vez que os processos seletivos tendem a ser mais rigorosos quanto aos prérequisitos de titulação e escolaridade, a aquisição de um trabalho formal pode ser facilitada pelo estudo formal. Dessa forma, possui o vetor estudo um aspecto qualitativo maior, por desempenhar um papel importante, direto e indireto, no aumento da renda.

Pela percepção da influência indireta do vetor estudo formal na aquisição de um trabalho formal, e diante da interdependência entre o aumento do número de fontes de renda e da ampliação da rede de contatos, é possível intuir dois principais vetores como determinantes para uma ascensão profissional no âmbito específico da música, e que estão em consonância com o consenso geral acerca da mobilidade social. Estes fatores são a atuação e o estudo. 


\section{Referências}

1. BRASIL (1960). Lei no 3.857, de 22 de dezembro de 1960. Cria a ordem dos músicos do Brasil e dispõe sobre a regulamentação do exercício da profissão de músico, e dá outras providências. Diário Oficial da União. Brasília, DF, 23 dez, p.16269.

2. ESTEVAM, V. (2010). "Ensino de música e evasão escolar em conservatórios de Minas Gerais: dois estudos de caso". Anais do SIMPOM, v.2, n.2. Rio de Janeiro: UFRJ.

3. FIGUEIREDO, F. F. (2006). "Educação superior e mobilidade social: Limites, Possibilidades e Conquistas”. São Paulo: PUC-SP.

4. GIOLO, S. R. (2010). Introdução à análise de dados categóricos com aplicações. Disponível em: <people.ufpr.br/ giolo/CE073/Material/Suely_Giolo.pdf>. Acessado em: março 2013.

5. MAGALHÃES, M. N.; LIMA, A. C. P. (2002). Noções de probabilidade e estatística. 5a ed. São Paulo: Edusp.

6. PERES, T. H. A. (2010). "Educação superior, emprego e renda: uma relação problemática. RMSP. 2002-2009”. Tese de Doutorado, USP. São Paulo, SP.

7. PICHONERI, D. F. M. (2006). "Músicos de orquestra: Um estudo sobre educação e trabalho no campo das artes". Biblioteca digital da Unicamp. Campinas, SP.

8 . (2011). "Relações de trabalho em música: a desestabilização da harmonia". Tese de Doutorado, Faculdade de Educação, Unicamp. Campinas, SP.

9. TRIOLA, M. F. (2008). Introdução à estatística. Tradução Vera Regina Lima de Farias e Flores, revisão técnica Ana Maria Lima de Farias. 10a ed. Rio de Janeiro: LTC.

Notas sobre os autores

Kássio Alves Mendes é Bacharel em Música com Habilitação em Flauta Transversal pela Escola de Musica da Universidade do Estado de Minas Gerais (ESMU-UEMG). Especialista em Princípios e Recursos Pedagógicos em Música pela ESMU-UEMG. É membro do Conselho de Políticas Culturais da cidade de Santa Luzia, MG.

Lívia Maria Dutra é Bacharela em Estatística pela Universidade Federal de Minas Gerais, licenciada em Música com Habilitação em Violino pela Escola de Música da Universidade 
do Estado de Minas Gerais e bolsista CAPES do programa de Pós-Graduação em Estatística da Universidade Federal de Minas Gerais.

Denise Perdigão Pereira é graduada em Educação Artística pela Escola Guignard da Universidade do Estado de Minas Gerais, mestre em Educação pela Pontifícia Universidade Católica de Minas Gerais. Foi professora de Prática de Ensino na Escola Guignard. Atualmente é professora de Metodologia Científica e coordenadora de trabalho de conclusão de curso na Escola de Música, também pertencente à Universidade do Estado de Minas Gerais. 